Brit. J. industr. Med., 1964, 21, 251.

\title{
THE FUTURE OF INDUSTRIAL MEDICINE IN GREAT BRITAIN*
}

\author{
BY \\ JOHN ROGAN \\ From the National Coal Board
}

(RECEIVED FOR PUBLICATION JULY 20, 1964)

My choice of subject may have surprised you. In recent years the future of industrial medicine has been debated and reported on by various committees and individuals, and you may think that enough has been written and said about it. Nevertheless there are, in my view, strong reasons in favour of a thorough and realistic survey of the future of our discipline at this time. First, ideas on the future of medicine as a whole in this country are in a state of flux-so far as general practice is concerned one might say in a state of ferment-and industrial medicine must find its proper place in the pattern that emerges. Second, industry, too, is on the threshold of rapid change, and this must be taken into account in thinking about the future. Third, a new government will be formed in a few weeks' time after the General Election. I intend to examine these three topics in turn, the future of medicine, the future of industry, and the political issue, and then to deal with the main theme of the lecture.

\section{The Future of Medicine}

Prophecy is a notoriously hazardous occupation, but one forecast will not be challenged and that is, the dynamic advance of medical science is bound to continue with increasing momentum. This will bring the profession and the community face to face with daunting problems of ethics and finance. It will also compel much hard thinking on the organization of medical practice in the widest sense. Clearly the situation must not be allowed to arise in which the provision of the best practicable medical service for the community is frustrated or hindered by the inadequacies of the organizational framework.

It is difficult to foresee the changes in organization that will take place in the next decade. There are,

*The Mackenzie Industrial Health Lecture delivered at the University of Sheffield on July 16, 1964. however, a number of pointers which we can consider. The most important of these is the report of the Medical Services Review Committee (1962), better known by the name of its distinguished Chairman, Sir Arthur Porritt. This Committee, which took four years to accomplish its task and represented the whole profession, reviewed all the medical services and made far-reaching proposals for their improvement. The most novel of these was designed to end the vexatious trichotomy of the three main parts of medical practice, the hospital service, general practice, and the public health service. The Committee recommended setting up Area Health Boards, which would integrate and administer all three services. The Committee also reviewed the occupational health services. They appreciated that there were three alternative lines of development. First, complete absorption and development within the National Health Service; second, parallel development of private and state services, the former associated with, and the latter administered by, the National Health Service; and third, further development of private services. Recognizing that there were arguments for and against each course, the Committee came down in favour of the second. Without going into detail as to how it was to be realized, the Committee recommended that the public sector should be administered by Area Health Boards. Each Area Health Board would be responsible for overall planning and development of all services, including occupational health, and for their administration. Subsidiary Councils would have charge of the administration of each service. Thus there would be an Occupational Health Services Council to supervise the public sector of medical care in industry and commerce and to ensure liaison with the private sector. In this way the public sector at least would be closely integrated with all other medical activities in each Area.

Other recommendations relating to industrial 
medicine were that all appointments of Industrial Medical Officers, whether public or private, should be subject to some degree of public control by the participation of specialists in the subject on selection boards, and that the Medical Inspectorate of Factories should be transferred to the Ministry of Health.

A very thorough survey of general practice was carried out recently by the Committee on the Field of Work of the Family Doctor (Ministry of Health, 1963), better known as the Annis Gillie Committee. Their report, which makes many practical proposals for the improvement of general practice, stresses the need for close association between general practitioners and hospitals in order that they may keep abreast of the 'almost explosive' advances in medicine and science. The general tenor of the report and the substance of current discussions in the medical press lead one to the view that general practice in its present form is now outmoded and that a completely new system may have to be evolved if it is to be saved from gradual attenuation.

The fundamental dissatisfactions with the present system appear to be the gulf between hospital and general practice, the failure of the present pay arrangements to reward merit and initiative, and the increasing difficulty in providing the wherewithal for the efficient practice of modern medicine, premises, secretarial assistance and so on. Thorough reform of general practice should, incidentally, remove the incentive to undertake outside commitments for financial considerations irrespective of real professional interest and inclination.

The Gillie Report has been criticized (Norman, 1963) on the grounds that it makes only slender reference to industrial medicine as a discipline to be pursued by general practitioners. But if one accepts the strong arguments about the need for fuller and continuing post-graduate education and considers the large number of subjects in which general practitioners have a special interest, the conclusion seems inescapable that general practitioners will in the future make only a comparatively small contribution to industrial medicine in terms of numbers.

A growing shadow over the next few years is the general shortage of medical manpower. It has become increasingly obvious that the forecasts of the Willinck Committee were substantially in error. Not only is there general concern about the future supply of general practitioners but it is now evident that a severe shortage of consultants is imminent. Moreover, the hospital service can hardly escape a crisis if the present contribution of foreign graduates to the junior and intermediate grades of staff diminishesand this seems very likely.

\section{The Future of Industry}

If it is difficult to forecast the future of medicine in the next decade, it is perhaps more difficult to forecast the future of industry. However, a number of trends can be discerned. The gradual reduction in trade barriers is increasing competition and placing a higher premium on efficiency. For some time past there has been a movement among firms working in the same or allied fields towards amalgamation so that their activities may be rationalized and coordinated. This process seems to be gathering momentum. Thus it is likely that the number of large units in industry will increase, and as manufacturing industry tends to become more capital intensive it also seems likely that the number of small units will decrease.

The drive for greater efficiency will require more flexibility. The increasing application of science to industrial processes is bound to result in a more rapid change in techniques as new developments succeed each other. Thus industry is certain to become more complex; the speed of advance in the chemical industry is a case in point.

Automation is certain to cause a very great change in industry. It seems bound to result either in a marked reduction in the labour force or in the hours generally worked in industry. If automation is indiscriminately and rapidly introduced, then the nation may be faced with an unemployment problem of the utmost severity. Already there are signs that this is beginning to happen in the United States of America. Another possible effect of automation is that, whereas the task of the operators will be much reduced, competitive industrial conditions will intensify the workload and increase the stress borne by the manager and designer. One might imagine that automation calls for intensive study and planning on a national basis, but it seems that no such measures are being taken.

The drama of automation should not lead us to ignore the earlier process of mechanization. This still continues apace, and in time it is likely to reduce the number of heavy jobs in industry.

\section{Political Attitudes to Industrial Medicine}

The attitude of the present Government to the development of industrial medicine has been made quite clear. It is to be left entirely to the initiative of the employer. The attraction of this policy, which is endorsed by the British Employers' Confederation (1964), is of course that an employer is free to provide his organization with an industrial medical service if he wants to and if he thinks he can afford it. Its principal weakness is that it permits the 
spending of part of the national income on industrial medical services which may be provided not according to need but by the ability and willingness to pay. In this respect, Government policy on industrial medicine is directly opposed to the ethical basis of the National Health Service, namely, that the service is available to all in case of need and without regard to means.

Another disturbing feature of Government policy is the association of industrial medicine with the Ministry of Labour. It is true that this Ministry is closely concerned with manufacturing industry, but the bounds of industrial medicine are far wider and include, e.g., the power industries, aviation, and public transport, for which it has no responsibility. Presumably this association is a legacy from the war years when a powerful Minister of Labour, Ernest Bevin, rapidly developed industrial medical services of a sort in factories. It is also true that the Medical Inspectorate of Factories and the Appointed Factory Doctors are administered by the Ministry of Labour.

Simple precedent, however, is not a forceful argument. So far as the Medical Inspectorate are concerned, it seems unlikely that expansion with recruits of good quality, which is generally thought to be necessary, will be possible until the Inspectorate is transferred to the Ministry of Health. The Appointed Factory Doctor system is the subject of recurrent debate as to its value in its present form in present conditions. Surely it, too, should be transferred to the Ministry of Health. Then the whole system could be reviewed and evaluated in the light of informed medical opinion.

One of the major handicaps of industrial medicine is isolation. This could only be aggravated if, consequent upon a change of Government policy to one of development of industrial medical services, these services were to be sponsored by the Ministry of Labour. The Ministry of Health, on the other hand, is the organization responsible for the administration of all the major health services in the country. It is thoroughly familiar with the medical problems of the nation and is the natural centre for the development of industrial medical services. Moreover, the growth of industrial medical services could readily be guided by the Ministry of Health in the direction of closer integration with the other health services.

Whereas the policy of the Conservative Party is one of laissez-faire, the policy of the Labour Party as enunciated in their booklet Members One of Another (Labour Party, 1959) is one of positive action. Indeed the booklet declares that Labour intends to create a full medical service. After the policy declaration the booklet gives a definition of a comprehensive occupational health service which includes the clause, 'the provision of accommodation for treatment at work, wherever such provision is justified in improving health and saving working time', which arouses the suspicion that what is meant here is general practice in the factory-and this is a misconception of industrial medicine. The booklet goes on to describe how occupational health services would be planned to cover all factories and other places of work region by region. Two years are given for planning, and then would come the phase of implementation, though this might take several years.

Though one may admire the vigour and sense of purpose which pervades the document a number of omissions must be noted. First it adduces no evidence of the need for a fully comprehensive occupational health service. Second, when discussing organization, it deals only in generalities. Third, it is silent on the question of financing the service. The document was issued before the imminent shortage of medical manpower was fully appreciated and makes no reference to the problem of how sufficient doctors are to be obtained.

\section{Review of Future Trends}

At this stage it may be convenient to sum up the foregoing discussion on future trends.

The dynamic advance in medical science is bound to continue. We cannot perhaps expect a new organization for medical care, integrating hospital, domiciliary, preventive, and industrial services, but at least we can urge it and hope for it. Far-reaching reforms are likely in general practice of such a nature that only the exceptional individual will have the time and inclination to practise industrial medicine.

Industry will continue to move in the direction of larger units by mergers and acquisitions. It will become increasingly competitive and will be characterized by growing technical complexity and by greater flexibility. Automation will present a socioeconomic problem which will tax the best brains in the country. These changes have important implications for industrial medicine in terms of security of tenure and the adequacy of post-graduate education.

Whichever party gains power at the General Election will be under pressure to develop industrial medical services. If the Conservative Party is returned we can anticipate that their policy will in the first instance continue to be one of inaction, but political parties are not immune from pressure and if enlightened opinion among employers and workers urges a change of policy with sufficient tenacity then a different outlook and policy may eventually prevail. On the other hand, if the Labour Party is 
successful, we may expect an early assessment of need and an attempt to provide a comprehensive occupational health service thereafter. In either case it is vital that the confidence of our profession should be retained, and this can only be achieved if we are fully consulted by the Government. It is therefore essential that we should be in a position to advance realistic and carefully thought out ideas and plans.

\section{The Future of Industrial Medicine}

An Occupational Health Service-Comprehensive or Selective?-I now come to the main theme of this lecture. A useful basis for discussion is the British Medical Association (B.M.A.) publication, The Future of Occupational Health Services (1961). It deals with policy, functions, organization, personnel, and equipment. The document states the B.M.A.'s position thus: 'The B.M.A. urges that an immediate beginning be made in setting up a comprehensive occupational health service'. The concept of a comprehensive occupational health service, also advocated by the Labour Party, is not new. Indeed, such a service, covering industry and non-industrial organizations, was recommended by the Dale Committee (Report of a Committee of Enquiry on Industrial Health Services, 1951). The validity of the concept, however, remains unproven. Admittedly the B.M.A. recommend that priority be given to places of work where, because of abnormal risks to health or their size, the need appears the most urgent. But they also say that a service should be made available as soon as possible to all workers in factories, businesses, shops, and farms. It could be argued that comprehensive means different things in different situations, but the B.M.A. document is quite uncompromising. Nor in discussing priority is hazard regarded as the sole criterion. Size is also mentioned, and the relevance of this factor is, generally speaking, dubious.

There are two powerful arguments against a comprehensive occupational health service in the full sense. In the first place, such a service is not required by a large sector of industry and commerce. In many factories and commercial organizations the hazard to health is negligible. It is true that an industrial medical officer, if appointed in these circumstances, can go through all the rigmarole of routine functions, but it is extremely doubtful if this is the proper use of scarce and highly skilled medical manpower. It can be postulated that in any industry or commercial organization there are problems of human relations and of stress and strain which the industrial medical officer can help to solve. This is no doubt true, but these problems per se hardly warrant a comprehensive occupational health service. Indeed, if the general practitioner of the future is to acquire the psychological and psychiatric skills advocated by the Gillie Committee, he should be able to deal effectively with these problems on an individual basis; granted, of course, that where an occupational health service is provided, after an overall assessment with the emphasis on hazards, the industrial medical officer should certainly be concerned with these matters and, with a special knowledge of the organization, may be more effective in dealing with them.

Secondly, when it is now certain that there will be a severe shortage of doctors for many years to come, it seems completely unrealistic to press for a comprehensive occupational health service 'as soon as possible'. It is only fair to add that the B.M.A. document, like the Labour Party statement, was written before the extent of the manpower shortage was apparent.

Surely the only valid criteria for a full occupational health service are the existence of a material hazard to health together with other relevant factors, such as the nature of the hazard, the impracticability of its effective control by other arms of the health service, and the facts of geography.

It is not, of course, my contention that industries and organizations which are free from hazard should be deprived of any medical assistance and supervision. Problems of simple hygiene and resettlement will arise from time to time. The public health service should be able to deal with the former and an expanded and appropriately trained and enlarged Medical Inspectorate of Factories with the latter.

Functions of an Occupational Health Service.-The statement on functions of occupational health services in the B.M.A. document, so far as it goes, is impeccable but unimaginative. It could hardly inspire the undergraduate to choose a career in industrial medicine. No mention is made of the great opportunities for epidemiological investigation. Research is mentioned in passing as something to be arranged elsewhere. Considerable reference is made to the assessment of health of individual workers and to routine examinations. This subject is big enough and difficult enough to warrant a separate lecture. Let it be said in passing, however, that routine examinations should never be instituted unless their value is obvious or can be convincingly demonstrated. The better the general health of the working population and the quality of the health services, the less necessary are routine examinations likely to be. In some instances, e.g., drivers of public service vehicles or airline pilots, routine examinations need no justification, but in many others they 
accomplish little and, if they occupy too much of his time, they lower the morale of the examining doctor. When routine examinations have to be done there is much to be said for incorporating them in a plan of epidemiological investigation. Lastly, the principle of delegation should be kept firmly in mind. It is my experience that occupational health nurses can be very effectively employed in appropriate circumstances to screen working groups, only referring to the doctor those cases with an abnormality and those about whom they have any doubts.

Organization.-The future organization of industrial medicine is an extremely formidable problem. It must, however, be solved one way or another sooner or later. If the medical profession do not put forward constructive and feasible proposals they can hardly complain if the solution adopted is unsatisfactory.

The three basic choices are mentioned in the Porritt Committee report and can be considered seriatim:

(i) Complete Absorption in the National Health Service.-This solution, the most radical and at first sight the simplest, would have certain positive advantages. It would end the professional isolation of the doctor in industry and would give him security of tenure. Here it may be observed that security of tenure may not be a wholly desirable thing. But when it obtains in substantial measure in all other branches of medicine, and is presumably generally favoured by the profession, it should also be granted to the same extent to the doctor in industry; otherwise the potential recruit may be deterred by the risk of dismissal. The service would certainly be provided on the basis of need as the Treasury would be most unlikely to agree to the provision of unnecessary services. But it would also have serious disadvantages. The best industrial medical services have developed over many years in such a way that they fit closely into the pattern of industry. The doctors working in them have become part of the management team and would be very much less effective if they could not continue in that role. The industries and firms concerned have a proper pride in their services. Much of their enthusiasm for industrial medicine might evaporate if these services were taken over by the State.

(ii) Part-private and Part-public.-This solution is something of a compromise but a reasonable one. The Porritt Committee envisaged existing industrial medical services continuing much as at present but with certain statutory safeguards which would generally be welcome. On the other hand, further necessary development, for which employers could not or would not be responsible, would be carried out by a unified National Health Service. Under this policy a serious beginning could be made to supply industrial medical services to the many concerns which need them. The main disadvantage in this course would seem to be the division of industrial medical services into two sectors, one private the other public. Cohesion, which is valuable in itself and not merely as a means of achieving a tidy administrative pattern, would be difficult to achieve. In the course of time the private sector might well grow away from the main body of medical practice and become a separate enclave. Another difficulty about this policy is finance. If employers who need a service could have it provided for them by the State without charge, there would be little incentive for them to develop such a service for themselves. Indeed a quite inequitable situation would exist if some employers, out of a sense of public duty, were providing an efficient industrial medical service at their own expense and at the same time their competitors whose need was equally great were enjoying a free service provided by the State.

(iii) Complete Independence of the National Health Service.-This is the situation as it now exists. Its disadvantages have already been enumerated. Its main attraction seems to be that it calls for no hard constructive thinking about the future but it will not provide the country with the industrial medical service it needs.

The three basic methods of organizing future industrial medical services have now been considered. Both the first and second have merits and disadvantages. The third can now be dismissed. On balance the second seems the most practicable and the best, and this was the view of the Porritt Committee. Is it possible to modify it so as to remove its defects and perhaps gain some of the advantages of the first method? It will simplify matters if we refer to it as the Porritt plan.

First there is the problem of cohesion between the private and public sectors of the industrial medical service. Both the Porritt Committee and the B.M.A. recommended the establishment of regional occupational health service councils. Under the Porritt plan the council would serve the region covered by the Area Health Board. Fairly full representation of the doctors in both private and public sectors on these councils would certainly promote cohesion and facilitate co-ordination. The division between the sectors could be further reduced if all doctors practising industrial medicine were employed by the National Health Service. The question then arises as to how this can be effected without impairing the pattern and functioning of existing efficient industrial medical services. A feasible solution would appear 
to be to employ the doctors in the private sector on joint contract with the National Health Service and their employers. They would then be members of the N.H.S. but could work in their own industry or firm on secondment. They would be paid by their employers at rates not less than those applicable in the public sector. Implicit in such an arrangement would be some measure of state control of all industrial medical services. Here the pattern of present industrial medical services must be taken fully into account. Some of these, for example in the nationalized industries and in the large firms, would be operating in more than one region. These services could only be supervised on a national basis, for example by an occupational health department of the Ministry of Health, advised by a national Occupational Health Services Council. Supervision of private industrial medical services operating within a region would be the task of the National Health Service administration at regional level, also advised by an Occupational Health Services Council. At this point the question may pertinently be asked, 'What is meant by supervision?'

It is visualized that supervision would be concerned primarily with efficiency, and in this connexion the financial problem mentioned earlier is relevant. This could be overcome by financing industrial medical services by a charge on all employers and employees as part of the general social insurance provision. Employers already providing an efficient and necessary industrial medical service would have their service approved and their contributions remitted. Similarly, employers planning a service according to the same criteria and with the capacity to do so would also be relieved of their contributions. It might happen that some firms whose operations were free from hazard wished to provide an industrial medical service as a 'fringe benefit'. They should surely be free to do so, but in that event their service would not be approved and no remission of their contributions would be justified.

Supervision should also be concerned with recruitment and appointment of doctors in industry and should ensure that they were of the necessary high quality in both the public and approved private sectors. General state supervision of this nature should incidentally go far to solving the problem of security of tenure. If industry in future is as flexible as has been forecast, the situation may not infrequently arise in which the competent doctor will find himself redundant through no fault of his own. Under this modification of the Porritt plan it should be comparatively easy to reabsorb him in either the private or public sector. Movement between the sectors to enlarge and broaden experience would also be facilitated. It is hardly necessary to add that the foregoing proposals and organization need not wait upon the major changes in the structure of the health service recommended by the Porritt Committee. They could be adopted on the basis of existing regions of the hospital service.

Staffing.-This survey of the future of industrial medicine would be incomplete without some consideration of the personnel who will be required to staff the service. A proper plan of development should contain an estimate of future vacancies and grades. Until a national survey of requirements has been carried out it will be impossible to frame this estimate. Assuming that it were available, however, it is most improbable that it could be met in conditions of an acute shortage of medical manpower. If indeed comparatively few recruits are likely to be forthcoming it is vital for the future of industrial medicine that they should be of good quality. They will not be obtained unless industrial medicine can be held out as a thoroughly satisfying and attractive career. The question then arises as to what sort of training the young post-graduate should receive. The answer depends on our conception of industrial medicine. When we consider the growing complexity of industry and the speed of advance in medical and scientific knowledge applied to industry, the conclusion seems inescapable that industrial medicine will become a whole-time speciality. This is not to ignore the debt owed by industrial medicine to a number of distinguished general practitioners nor to say that there is no place for the part-time industrial medical officer in the future, but the logic of events must make such appointments increasingly rare.

It is certainly true that the majority of the present generation of doctors in the industry have learnt their subject on the job. While there is much to be said for this type of training it will not in future be sufficient.

Industrial medicine is unique in being a combination of preventive and clinical medicine. In my view, the doctor in industry in the future will require a minimum of one year's full-time university study and should have to pass an examination for the Diploma of Industrial Health much wider in scope and more searching than it is at present. The B.M.A. (The Future of Occupational Health Services, 1961) is convinced that there is a need for more postgraduate training in industrial medicine'. This may well be true so far as refresher courses are concerned, but there is perhaps a greater need for intensification of primary training. This would increase the teaching load on university departments which could only be acceptable if they were strengthened in terms of staff and finance, otherwise the balance between teaching 
and research would be disturbed. For doctors aspiring to the higher posts in industry, membership of one of the Royal Colleges of Physicians is likely to be a basic requirement. A membership is often regarded as a specialist qualification per se whereas it is simply intended to indicate that its possessor is potentially of consultant status.

The grading of doctors in industry is likely to be of great importance. Unless the grade structure is reasonably attractive and devised to take proper account of promotion prospects good recruits will not be forthcoming. Under present conditions the existing grade structure, which has been evolved due to the initiative of the B.M.A., is probably as good as it can be. The medical officer grade, which must include the majority of doctors in industry, should probably lie about mid-way between the general practitioner and the consultant in financial standing in view of the specialist nature of the post and the time required in training. In future it may be desirable for the senior medical officer grade to be exactly equated with the consultant grade in the hospital service. The higher posts in industrial medicine, i.e., S.M.O. and above, should certainly carry their fair share of distinction awards.

Industrial medicine is a speciality which, to an unusual degree, requires collaboration between doctors and other professional people. The efficient investigation and control of environmental hazards frequently calls for teamwork among doctors, scientists, engineers, and sometimes statisticians. Many non-medical graduates in industry are already carrying out this collaborative work, commonly referred to as occupational hygiene, on a substantial scale, either whole-time or part-time, and it is now possible for them to receive formal training in the subject.

Recently there have been many understandable expressions of regret at the demise of the Slough Occupational Hygiene Laboratory Service. It is most surprising that from industry in the southern counties sufficient work was not forthcoming to keep that service fully occupied and solvent. It may be that a location in London would have been better. It is also possible that the concept of occupational hygiene as something done in a laboratory, which is implied by the title 'occupational hygiene laboratory service', is too restrictive. In any event few would dissent from the view that one essential phase in a national survey of the need for industrial medical services would be a thorough assessment of the resources available for occupational hygiene, taking into account industry itself, the research organizations, the universities, and the factory inspectorate.
Thus the future requirements for an occupational hygiene service could be determined and the gaps filled. This will involve the recruitment and employment of engineers and scientists, not necessarily on a large scale, by the public sector of industrial medicine. Here it must be observed that the record of the National Health Service in providing satisfactory conditions of service for scientists is undistinguished. The fact that scientists in medicine are likely to remain a minority group must not be allowed to obscure their importance. It is as true of industrial medicine as of other branches that unless good conditions are offered to non-medical graduates, vacancies will be filled by candidates of inferior calibre and progress will be impeded.

The importance of the nurse in industry needs no emphasis. When doctors are certain to be scarce the contribution the nurse can make to the future of industrial medicine requires full and careful consideration. Presently efforts are being made to improve the status and the education of the nurse. The more successful this process the better for industrial medicine. The more capable and intelligent the nurse the more readily can the doctor delegate work to her which by tradition would have been done by himself.

Research.- - It is tempting to survey the future of research in industrial medicine. Research is, however, a very complex subject which cannot be dealt with adequately in brief compass. Suffice it to say that, even if all the problems referred to earlier have been solved, the practice of industrial medicine will not progress unless it is informed and stimulated by an adequate amount of research of good quality.

\section{Conclusion}

Reflecting on the lack of any material advance of industrial medicine in recent years, on the negative attitude of the responsible authorities, and on the apathy of many employers, it seems to me that some responsibility for this state of affairs may be attributed to the persistent advocacy of a rapid and undiscriminating expansion of industrial medical services. The arguments and proposals advanced in this lecture may not be congenially received in all quarters but they seem to me to be realistic and justifiable. In advancing them $I$ have had the sole purpose in mind of suggesting a form for industrial medicine which can meet the needs of industry without excess or extravagance and which can ensure that industrial medicine will remain not only viable but full of promise for the future. 
Note

The opinions and views expressed in this lecture, other than those quoted, are solely those of the writer.

\section{REFERENCES}

British Employers Confederation (1964). Trans. Ass. industr. med. Offrs, 13, 106.
Labour Party (1959). Members One of Another: Labour's Policy for Health. London.

Medical Services Review Committee (1962). A Review of the Medical Services in Great Britain. Social Assay, London.

Ministry of Health (1963). The Field of Work of the Family Doctor. Ministry of Health (1963).

Norman, L. (1963). Brit. med. J., 2, 996.

Report of a Committee of Enquiry on Industrial Health Services (1951). H.M.S.O., London.

The Future of Occupational Health Services (1961). British Medical Association, London. 